\title{
BMJ Open Comparative efficacy and safety of approved treatments for macular oedema secondary to branch retinal vein occlusion: a network meta-analysis
}

\author{
Stephane A Regnier, ${ }^{1}$ Michael Larsen, ${ }^{2}$ Vladimir Bezlyak, ${ }^{1}$ Felicity Allen ${ }^{3}$
}

To cite: Regnier SA, Larsen M, Bezlyak V, et al. Comparative efficacy and safety of approved treatments for macular oedema secondary to branch retinal vein occlusion: a network meta-analysis. BMJ Open 2015:5: 007527.

doi:10.1136/bmjopen-2014007527

- Prepublication history and additional material is available. To view please visit the journal (http://dx.doi.org/ 10.1136/bmjopen-2014007527)

Received 24 December 2014 Accepted 23 April 2015

\section{CrossMark}

\section{${ }^{1}$ Novartis Pharma AG, Basel, Switzerland \\ ${ }^{2}$ Department of Ophthalmology, Glostrup Hospital, University of Copenhagen, Glostrup Denmark \\ ${ }^{3}$ Novartis Pharmaceuticals UK Ltd., Frimley, Camberley, \\ Surrey, UK}

\section{Correspondence to}

Stephane Régnier;

stephane.regnier@novartis. com

\begin{abstract}
Objective: To compare the efficacy and safety of approved treatments for macular oedema secondary to branch retinal vein occlusion (BRVO).

Design: Randomised controlled trials (RCTs) evaluating the efficacy and safety of approved treatments for macular oedema secondary to BRVO were identified from an updated systematic review.
\end{abstract}

Setting: A Bayesian network meta-analysis of RCTs of treatments for macular oedema secondary to BRVO.

Interventions: Ranibizumab $0.5 \mathrm{mg}$ pro re nata, aflibercept $2 \mathrm{mg}$ monthly (2q4), dexamethasone $0.7 \mathrm{mg}$ implant, laser photocoagulation, ranibizumab +laser, or sham intervention. Bevacizumab and triamcinolone were excluded.

Outcome measures: Efficacy outcomes were mean change in best corrected visual acuity (Early Treatment Diabetic Retinopathy Study scale) and the percentage of patients gaining $\geq 15$ letters. Safety outcome was the percentage of patients with increased intraocular pressure (IOP)/ocular hypertension $(\mathrm{OH})$.

Results: 8 RCTs were identified for inclusion with 1743 adult patients. The probability of being the most efficacious treatment at month 6 or 12 based on letters gained was $54 \%$ for ranibizumab monotherapy, $30 \%$ for aflibercept, $16 \%$ for ranibizumab plus laser (adjunctive or prompt), and 0\% for dexamethasone implant, laser or sham. The probability of being the most efficacious treatment for patients gaining $\geq 15$ letters was $39 \%$ for aflibercept, $35 \%$ for ranibizumab monotherapy, $24 \%$ for ranibizumab plus laser, $2 \%$ for dexamethasone implant, and less than $1 \%$ for laser or sham. There was no statistical difference between ranibizumab monotherapy and aflibercept for letters gained $(+1.4$ letters for ranibizumab vs aflibercept with $95 \%$ credible interval (Crl) of -5.2 to +8.5 letters) or the $\mathrm{OR}$ for gaining $\geq 15$ letters: $1.06(95 \% \mathrm{Crl} 0.16$ to 8.94)). Dexamethasone implant was associated with significantly higher $10 \mathrm{P} / \mathrm{OH}$ than antivascular endothelial growth factor agents (OR $13.1(95 \% \mathrm{Crl}$ 1.7 to 116.9$)$ ).

Conclusions: There was no statistically significant difference between ranibizumab and aflibercept.

\section{Strengths and limitations of this study}

- Randomised controlled trials (RCTs) evaluating the efficacy and safety of approved treatments for macular oedema secondary to branch retinal vein occlusion (BRVO) were identified from a published systematic review and database searches.

- Inclusion/exclusion criteria for the key variables baseline BCVA and duration of disease were matched in the RCTs evaluating antivascular endothelial growth factor (VEGF) therapy.

- Despite matching for baseline best corrected visual acuity (BCVA) and duration of disease, substantial heterogeneity existed between anti-VEGF RCTs.

- Two clinical trials included in the meta-analysis were unpublished, and therefore their quality could not be assessed.

- For one study, the SE for letters gained was graphically estimated. For another study, the SD was assumed.

\section{INTRODUCTION}

Branch retinal vein occlusion (BRVO) and central retinal vein occlusion (CRVO) are important causes of visual impairment, and are thought to be the result of thrombotic events, external compression, or vessel wall pathology. ${ }^{1-3}$ Occlusion of the major veins of the retinal circulation leads to increased intraluminal pressure, haemorrhage and oedema. Macular oedema secondary to RVO (BRVO or CRVO) is the second most common retinal vascular disease after diabetic retinopathy. ${ }^{4}$

The treatment of choice for patients with macular oedema associated with BRVO has long been considered to be grid laser photocoagulation..$^{6-8}$ However, the recent introduction of pharmacotherapies specifically targeting vascular endothelial growth factor (VEGF), such as ranibizumab and aflibercept, 
has widened the range of therapeutic options. The efficacy of ranibizumab, a monoclonal anti-VEGF antibody fragment, in the treatment of BRVO was demonstrated in the Branch Retinal Vein Occlusion: Evaluation of Efficacy and Safety (BRAVO) phase 3 trial. ${ }^{9}$ Following publication of these results, ranibizumab was approved in the $\mathrm{USA}^{10}$ and $\mathrm{EU}^{11}$ for the treatment of macular oedema secondary to RVO. The efficacy of aflibercept, an anti-VEGF binding protein, was demonstrated in the VIBRANT phase 3 trial, ${ }^{12}$ and aflibercept has been submitted for approval in macular oedema secondary to BRVO in the EU. ${ }^{13}$ An intravitreal dexamethasone implant is approved for patients with macular oedema secondary to RVO. ${ }^{14} 15$ Other therapies include triamcinolone, a corticosteroid with a mechanism of action similar to dexamethasone, which is used off-label in this treatment setting; ${ }^{16-18}$ and bevacizumab, an anti-VEGF agent, which is not licensed for the treatment of visual impairment of any aetiology. Thus, triamcinolone and bevacizumab were both excluded from the current analysis.

Given the number of treatments that have been developed for RVO, there is a need for an evidence-based analysis of the comparative efficacy of the different treatments available. With this in mind, Glanville et $a l^{19}$ recently published a systematic review of randomised controlled trials (RCTs) evaluating the efficacy and safety of widely used treatments for macular oedema secondary to RVO. The main findings were that both ranibizumab and dexamethasone implants produced significantly greater improvements in best corrected visual acuity (BCVA) at 6 months in patients with RVO, when compared with individuals receiving sham intervention.

The current analysis adds to the Glanville $e t a l^{19}$ study by conducting a Bayesian network meta-analysis of all relevant RCTs, with the aim of comparing the efficacy and safety of all currently approved treatments or treatments submitted for approval for macular oedema secondary to RVO, comprising ranibizumab $0.5 \mathrm{mg}$, aflibercept $2 \mathrm{mg}$, dexamethasone $0.7 \mathrm{mg}$ implant and laser photocoagulation.

\section{METHODS}

\section{Glanville et al study}

In brief, this was a systematic review of RCTs reporting the efficacy and safety of available treatments for macular oedema secondary to RVO. ${ }^{19}$ The literature search was performed on 18 November 2010 using the databases Medline (including Medline In-Process), EMBASE, the Cochrane Library and Cumulative Index to Nursing and Allied Health Literature. Additional searches were performed in the ClinicalTrials.gov registry and the Association for Research in Vision and Ophthalmology (ARVO) database. The interventions included in the searches were ranibizumab, bevacizumab, dexamethasone and laser photocoagulation (bevacizumab was not included in our analysis). Primary efficacy outcomes were mean change in BCVA from baseline to month 6 (assessed in terms of Early Treatment Diabetic Retinopathy Study (ETDRS) letters) and the number of patients gaining at least 10 letters from baseline to month 6 . To be included, studies had to be RCTs that reported at least one primary efficacy outcome. The number of patients gaining at least 15 letters were also reported if available. In addition, RCTs had to comprise at least two treatment arms, including one active comparator of interest. Only RCTs in English were considered.

\section{Updated search strategy}

An updated search of Medline (including Medline InProcess), EMBASE and the Cochrane Library, using the search terms described in the study by Glanville et al (see online supplementary materials), was performed on 4 August 2014 to identify relevant RCTs that had been published since November 2010 (the date of the earlier study). Studies published in English, French and German were considered eligible for inclusion in the review.

\section{Inclusion/exclusion criteria for the network meta-analysis}

To be included in the current analysis RCTs had to meet the following criteria: (1) report at least one efficacy outcome of interest (mean change in BCVA from baseline or percentage of patients gaining $\geq 15$ letters from baseline); (2) the outcome of interest had to be measured at 6 or 12 months from study baseline, with 6-month data used for the analysis when available; (3) have at least two interventions of interest, including sham injections, ranibizumab $0.5 \mathrm{mg}$ monthly or pro re nata (PRN; as needed), aflibercept $2 \mathrm{mg}$ monthly (2q4), dexamethasone $0.7 \mathrm{mg}$ implant (retreatment interval $\geq 6$ months) and prompt laser photocoagulation therapy; (4) patients receiving anti-VEGF had a PRN or monthly regimen. RCTs in which efficacy data for BRVO and CRVO were not presented separately were excluded.

\section{Data sources and extraction}

RCTs evaluating the efficacy and safety of treatment for macular oedema secondary to RVO were identified from three main sources: (1) the study by Glanville et $a l^{19}$ (2) the updated search strategy described above and (3) manual searches of the ClinicalTrials.gov registry, proprietary data on file at Novartis Pharma AG, and abstracts from ophthalmology congresses, including ARVO, American Academy of Ophthalmology (AAO) and European Society of Retina Specialists (EURETINA) congresses. To the best of our knowledge, there were no additional relevant proprietary data on file at Genentech.

Study characteristics, including baseline characteristics, number of patients, country and key inclusion/ exclusion criteria, and study quality, were captured in Microsoft Excel spreadsheets.

\section{Study quality assessment}

The quality of each RCT was assessed according to the methodology checklist detailed in Appendix C of the National Institute for Health and Care Excellence 
Guidelines Manual 2012. ${ }^{20}$ In brief, these guidelines allow for assessment of the likelihood of bias in selection (systematic differences between comparator groups), attrition (systematic differences between comparator groups with respect to loss of participants), detection (systematic differences in how outcomes are ascertained, diagnosed or verified) and performance (systematic differences between comparator groups in the care provided, other than in the intervention under investigation).

\section{Network meta-analysis}

A Bayesian network meta-analysis with random treatment effects was used to compare mean change in BCVA from baseline to month 6 , OR for gaining at least 15 letters, and OR for an increase in intraocular pressure (IOP)/ ocular hypertension $(\mathrm{OH})$ across the RCTs. The model did not converge when we consider IOP/OH rates separately for ranibizumab and aflibercept. As the rates of increased IOP/OH were small and comparable for ranibizumab (0-5\%) and aflibercept (2\%), rates of increased $\mathrm{IOP} / \mathrm{OH}$ for ranibizumab and aflibercept were pooled to give an anti-VEGF rate of increased IOP/OH. This assumption is discussed in the Results section.

To estimate the posterior distribution for each model, two Markov chain Monte Carlo simulations were initialised using 27000 iterations for each simulation. However, results are reported after excluding the first 2000 iterations (ie, results are reported for 25000 iterations per chain). A $95 \% \mathrm{CrI}$ was created using the 2.5 and 97.5 centiles of the posterior distribution. The overall relative treatment effect was calculated using the median value from the posterior distribution. A relative treatment effect was interpreted as significant if the $95 \%$ CrI for the OR did not include 0 or if the $95 \%$ CrI for the BCVA gains did not include $0 .^{21}$ Analyses were performed using WinBUGS V.1.4 (MRC Biostatistics Unit, Cambridge, UK).

\section{Sensitivity analyses}

Several sensitivity analyses were conducted to assess the robustness of the network meta-analysis. The results of a fixed effects and random effects model were compared. The impact of removing RCTs that did not capture outcomes at 6 months was analysed, as was the impact of excluding RCTs with substantially lower baseline BCVAs than the other RCTs. In addition, we evaluated the impact of including the Ranibizumab for Branch Retinal Vein Occlusion Associated Macular Edema Study (RABAMES), ${ }^{22}$ in which the ranibizumab regimen was three doses at monthly intervals followed by a 3-month observation period. Finally, node-splitting analyses were used to compare the direct and indirect evidence of the efficacy of ranibizumab versus laser, ranibizumab versus dexamethasone implant and laser versus sham intervention. In the node-splitting analyses, the two-sided $p$ value for the probability that the direct effect differed from the indirect effect was given by $2(1-\mathrm{pr})$, if $\mathrm{pr}$ was $\geq 50 \%$ (where pr is the probability that the direct effect was greater that the indirect effect); if pr was $<50 \%$, the $p$ value for the probability that the direct effect differed from the indirect effect was 2 pr.

\section{RESULTS}

\section{Studies}

Glanville $e t a l^{19}$ identified six potentially relevant studies of patients with BRVO: the Branch Vein Occlusion Study (BVOS) ${ }^{7}$ Group trial, Battaglia Parodi et $a l^{8}{ }^{8}$ GENEVA, ${ }^{14}$ BRAVO,${ }^{23}$ Moradian et al, ${ }^{24}$ and Russo et al.${ }^{25}$ An additional study $^{26}$ included both individuals with BRVO and those with CRVO. ${ }^{26}$ On full text evaluation, three studies met the inclusion criteria and were included in the analysis $\left(\mathrm{BRAVO},{ }^{23} \mathrm{GENEVA}^{14}\right.$ and Battaglia Parodi $\left.e t a \mathrm{l}^{8}\right)$. BVOS was excluded because the efficacy data were presented at 36 months. The studies by Moradian $e t a l^{4}$ and Russo et $a l^{25}$ were also excluded because they did not include two treatments of interest. Finally, the Kuppermann $e t a l^{26}$ trial was excluded because it did not present separate efficacy outcome results for BRVO and CRVO.

The updated systematic review identified eight potentially relevant RCTs; however, full-text screening found that only one of these, Tan $e t a l,{ }^{27}$ met the inclusion criteria. In RABAMES, ${ }^{22}$ patients received only three injections of ranibizumab $0.5 \mathrm{mg}$ at monthly intervals, which were then followed by 3 months of observation. The number of injections was substantially lower than in the other studies evaluating ranibizumab, so the RABAMES $^{22}$ results were included only for sensitivity analysis. Three trials were excluded because these were extension studies ${ }^{1528} 29$ and three trials were excluded because they evaluated only one treatment of interest. $^{24} 30 \quad 31$ Manual searching identified three further trials (BRIGHTER, ${ }^{32}$ COMRADE-B ${ }^{33}$ and VIBRANT ${ }^{12}$ ).

The quality of the published studies is reported in table 1. In general, the studies were of good quality, with the exception of the study by Battaglia Parodi et $a l^{8}$ which did not report most of the key quality assessment components.

A Preferred Reporting Items for Systematic Reviews and Meta-Analyses (PRISMA) flow diagram showing the screening and selection process is presented in figure 1 . The network of studies, comprising a total of 1743 adult patients for the efficacy analysis, is presented in figure 2. In total, seven RCTs were identified for the analysis: BRAVO,${ }^{9}$ VIBRANT, ${ }^{12}$ Tan, ${ }^{27}$ GENEVA, ${ }^{14}$ BRIGHTER, ${ }^{32}$ COMRADE-B, ${ }^{33}$ and Battaglia Parodi et al. ${ }^{8}$ RABAMES $^{22}$ was used in sensitivity analysis. Outcomes were reported at month 6 in all studies except the study by Tan et $a l^{27}$ for which outcomes were reported at month 12, and Battaglia Parodi $e t a l,{ }^{8}$ for which outcomes were reported at months 3 and 12 .

\section{Treatment regimens}

Three studies (Tan et al., ${ }^{27}$ BRIGHTER ${ }^{32}$ and COMRADE- $\mathrm{B}^{33}$ ) reported results with a ranibizumab PRN regimen (table 2). BRAVO $^{9}$ was the only ranibizumab 


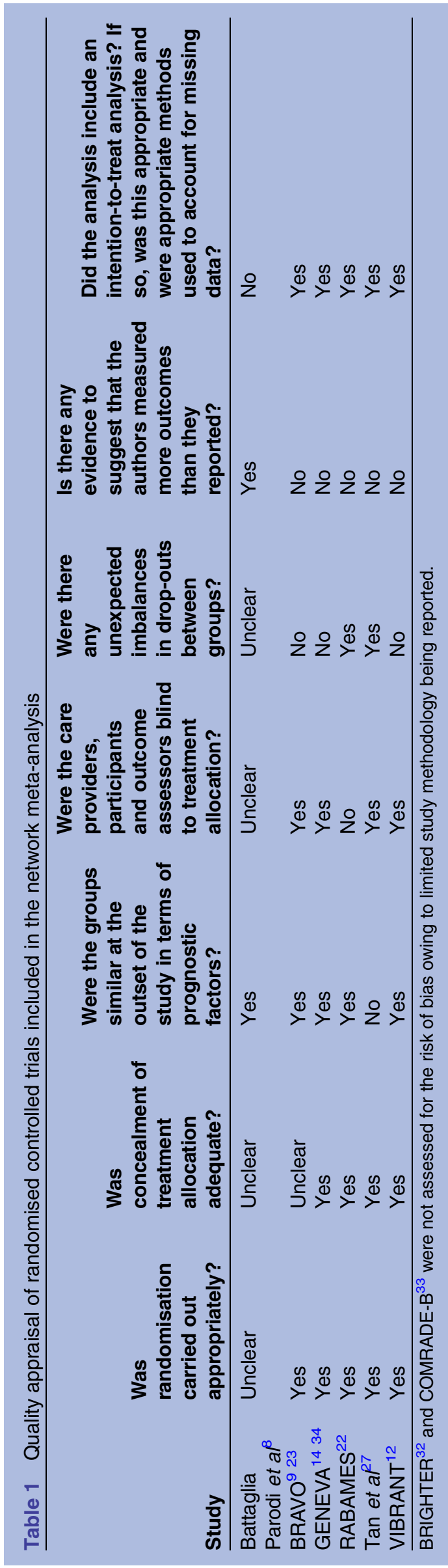

study in which results were reported after patients received six monthly doses of ranibizumab. Hence, for the purpose of this analysis, the ranibizumab treatment regimen is referred to as PRN. The mean number of injections in the first 6 months was 5.7 for aflibercept in VIBRANT ${ }^{12}$; this compared with 4.8 in BRIGHTER, ${ }^{32} 4.9$ in COMRADE-B ${ }^{39}$ and 5.7 in BRAVO $^{9}$ for ranibizumab.

In Battaglia Parodi et al, ${ }^{8}$ the mean BCVA gains from baseline at months 3 and 12 were used in the analysis as a proxy for the efficacy at month 6 . We could not use the SDs from Battaglia Parodi et $a l^{8}$ because these were reported on a non-linear transformation of the ETDRS. Instead, we assumed that the $\mathrm{SD}$ was the same as for BRAVO (13.2), ${ }^{9}$ which is in the mid-range of SD values in table 2 (minimum: 7.5; maximum: 19.3).

\section{Network meta-analysis}

Eligibility criteria differed among RCTs (see online supplementary table 1). Therefore, patient-level data for three of the ranibizumab trials (BRAVO, ${ }^{9}$ BRIGHTER $^{32}$ and COMRADE- $\mathrm{B}^{33}$ ) were reanalysed to match the key eligibility criteria from the VIBRANT aflibercept study ${ }^{12}$ (ie, criteria relating to BCVA and duration of disease at baseline). Specifically, patients were excluded from the analysis if they had a baseline BCVA of less than 24 letters or a duration of disease of more than 12 months. Using these criteria, only three patients were excluded from $\mathrm{BRAVO}^{9}$ and three patients were excluded from COMRADE-B ${ }^{33}$ but 91 of $448(20.3 \%)$ patients were excluded from BRIGHTER. ${ }^{32}$ The exclusion of these patients did not, however, create a major imbalance between treatment arms in BRIGHTER (see online supplementary tables 2 and 3). The baseline characteristics and efficacy outcomes of interest after this step are shown in table 2. Rates of increased $\mathrm{IOP} / \mathrm{OH}$ are presented in table 3.

Statistically significant mean $(95 \% \mathrm{CrI})$ changes in BCVA from baseline were found for ranibizumab monotherapy (+11.5 (7.5 to 15.9$))$, ranibizumab plus laser combination therapy $(+10.1(5.1$ to 15.3$))$ and aflibercept $(+10.2$ (4.6 to 15.5)) when compared with laser therapy alone (table 4$)$, and for ranibizumab monotherapy versus dexamethasone implant (+8.0 (4.0 to 11.9)) . Pairwise ORs for gaining at least 15 letters and absolute letters gains from baseline in the random treatment effects model are presented in tables 5 and 6 . Only ranibizumab monotherapy was statistically superior to laser therapy alone. OR (95\% CrI) compared with laser therapy were 3.24 (1.03 to 12.56) for ranibizumab monotherapy and 3.07 (0.63 to 14.8) for aflibercept. Mean (95\% CrI) BCVA letter gains were not statistically significant for ranibizumab monotherapy versus aflibercept $(+1.4$ letters $(-5.2$ to 8.5$))$ and the OR $(95 \%$ CrI $)$ for gaining at least 15 letters was 1.06 (0.16 to 8.94)). Patients treated with dexamethasone implant had statistically significant higher rates of $\mathrm{IOP} / \mathrm{OH}$ than those receiving the anti-VEGF monotherapies (OR 13.1 (1.7 to 116.9)). 


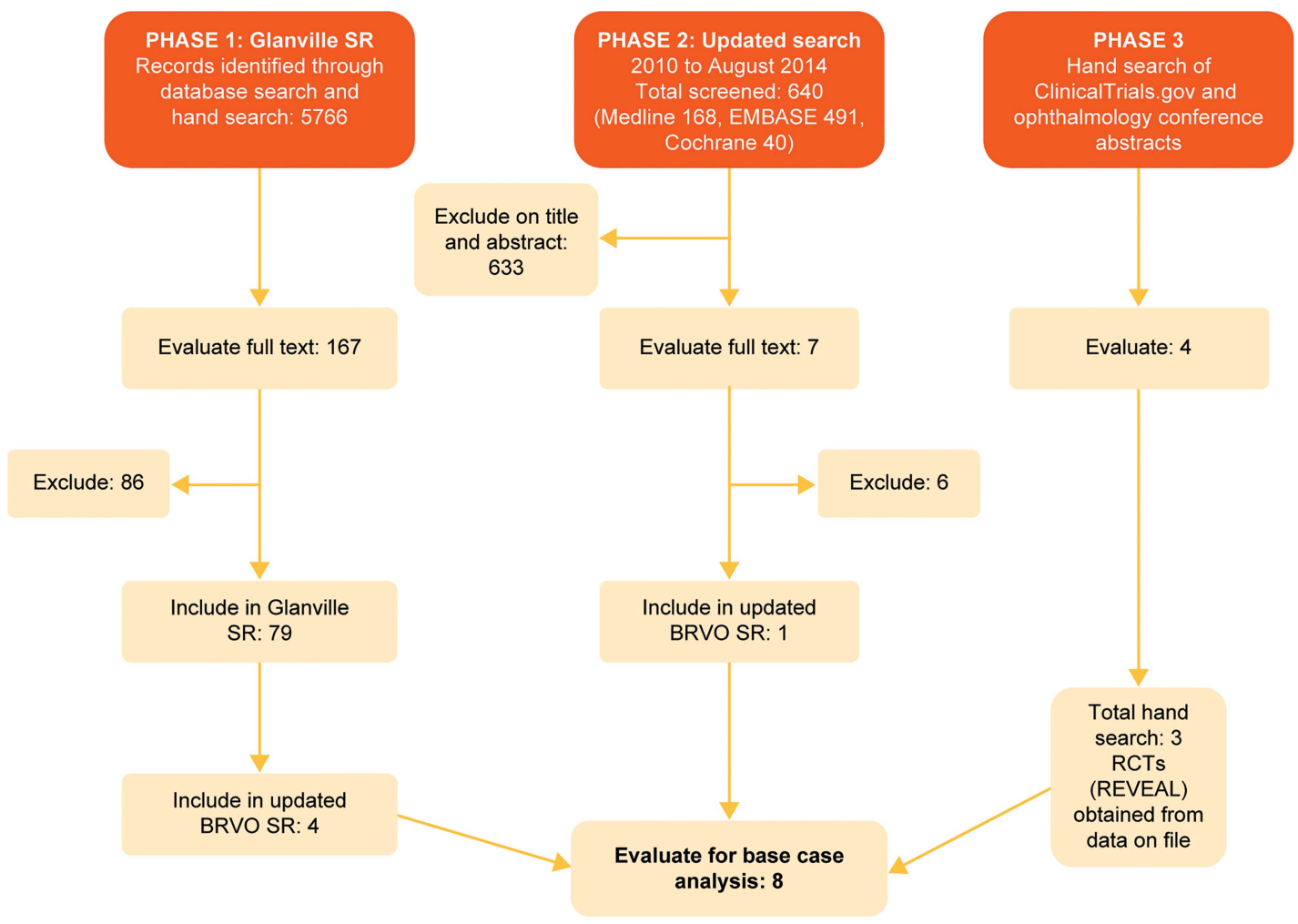

Figure 1 Preferred Reporting Items for Systematic Reviews and Meta-Analyses (PRISMA) flow diagram. BRVO, branch retinal vein occlusion; RCT, randomised controlled trial; SR, systematic review.

The probabilities of being the most efficacious treatment in the study network are presented in figure 3 . The probability of being the most efficacious treatment based on BCVA letters gained was $54 \%$ for ranibizumab monotherapy, $30 \%$ for aflibercept and $16 \%$ for ranibizumab plus laser photocoagulation, and $0 \%$ for dexamethasone $0.7 \mathrm{mg}$ implant. The probability that ranibizumab monotherapy is a better treatment than aflibercept is $67 \%$ (based on BCVA letter gained), which can be interpreted as follows: if 100 patients receive ranibizumab monotherapy in the right eye and aflibercept in the left eye, assuming the right and left eyes have the same baseline characteristics, on average, 67 patients would have a bigger gain observed in the right eye than in the left eye. The probability of being the most efficacious treatment based on the percentage of patients gaining at least 15 letters was $39 \%$ for aflibercept, $35 \%$ for ranibizumab monotherapy, $24 \%$ for ranibizumab plus laser photocoagulation, $2 \%$ for dexamethasone, $1 \%$ for sham intervention and $<1 \%$ for laser monotherapy. On the basis of the percentage of patients gaining at least 15 letters, the probability that ranibizumab monotherapy is a better treatment than aflibercept is $53 \%$.

Figure 2 Meta-analysis study network.

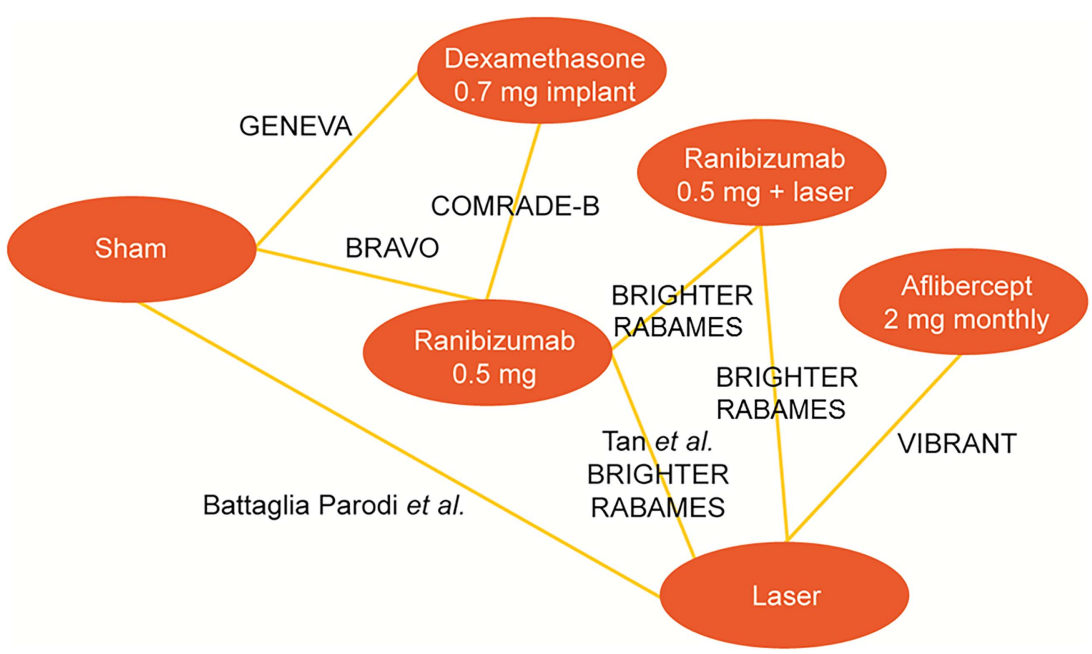


Table 2 Baseline patient characteristics and efficacy outcomes

\begin{tabular}{|c|c|c|c|c|c|c|c|c|c|c|c|}
\hline Study & Treatment (dose) & $\begin{array}{l}\text { Time end point } \\
\text { measured } \\
\text { (months) }\end{array}$ & Drug regimen & $\begin{array}{l}\text { Mean number } \\
\text { of injections/ } \\
\text { implants }\end{array}$ & $\mathbf{n}$ & $\begin{array}{l}\text { Baseline } \\
\text { BCVA }\end{array}$ & $\begin{array}{l}\text { Age } \\
\text { (years) }\end{array}$ & $\begin{array}{l}\text { Disease } \\
\text { duration } \\
\text { (months) }\end{array}$ & $\begin{array}{l}\text { Baseline } \\
\text { CRT }(\mu \mathrm{m})\end{array}$ & $\begin{array}{l}\text { Patients } \\
\text { gaining } \geq 15 \\
\text { letters }(\%)\end{array}$ & $\begin{array}{l}\text { BCVA } \\
\text { increase } \\
\text { (SD) }\end{array}$ \\
\hline \multirow[t]{2}{*}{ VIBRANT $^{12}$} & Aflibercept 2q4 & 6 & $\begin{array}{l}6 \times \text { monthly } \\
\text { doses }\end{array}$ & 5.7 & 91 & 58.6 & 67.0 & 1.4 & 559 & 53 & $17.0(11.9)^{*}$ \\
\hline & Laser & 6 & - & & 90 & 57.7 & 63.9 & 1.4 & 554 & 27 & $6.9(12.9)^{\star}$ \\
\hline \multirow[t]{2}{*}{ BRAVO† } & $\begin{array}{l}\text { Ranibizumab } \\
0.5 \mathrm{mg}\end{array}$ & 6 & $\begin{array}{l}\text { 6xmonthly } \\
\text { doses }\end{array}$ & 5.7 & 129 & 53.7 & 67.2 & 3.2 & $544 \ddagger$ & 60 & $18.1(13.2)$ \\
\hline & Sham injection & 6 & - & & 131 & 55.0 & 65.1 & 3.5 & $488 \ddagger$ & 29 & $7.3(13.1)$ \\
\hline \multirow[t]{2}{*}{ Tan et $a^{P^{7}}$} & $\begin{array}{l}\text { Ranibizumab } \\
0.5 \mathrm{mg}\end{array}$ & 12 & $\begin{array}{l}\text { 6xmonthly } \\
\text { doses, then } \\
\text { PRN }\end{array}$ & 8.1 & 15 & 39.5 & 69.6 & 4.1 & $616 \ddagger$ & 53 & $12.5(19.3)$ \\
\hline & Laser & 12 & - & & 21 & 46.2 & 66.7 & 3.5 & $519 \ddagger$ & 19 & $-1.6(18.2)$ \\
\hline \multirow[t]{2}{*}{ GENEVA $^{14} \S$} & $\begin{array}{l}\text { Dexamethasone } \\
0.7 \mathrm{mg} \text { implant }\end{array}$ & 6 & $\begin{array}{l}1 \text { implant at } \\
\text { month } 0\end{array}$ & 1.0 & 291 & 54.3 & 64.7 & 5.2 & 562 & 23 & $7.4(7.6) \S$ \\
\hline & Sham procedure & 6 & - & & 279 & 54.8 & 63.9 & 5.1 & 539 & 20 & $4.9(7.5) \S$ \\
\hline \multirow[t]{3}{*}{ BRIGHTER $\dagger$} & $\begin{array}{l}\text { Ranibizumab } \\
0.5 \mathrm{mg}\end{array}$ & 6 & $\begin{array}{l}3 \times \text { monthly } \\
\text { doses, then } \\
\text { PRN }\end{array}$ & 4.8 & 142 & 58.9 & 63.9 & 3.4 & $554 \ddagger$ & 50 & $16.3(10.2)$ \\
\hline & $\begin{array}{l}\text { Ranibizumab } \\
0.5 \mathrm{mg}+\text { laser }\end{array}$ & 6 & $\begin{array}{l}\text { 3xmonthly } \\
\text { doses, then } \\
\text { PRN }\end{array}$ & 4.5 & 143 & 56.7 & 66.7 & 3.2 & $582 \ddagger$ & 48 & $15.0(11.8)$ \\
\hline & Laser & & - & & 72 & 58.3 & 67.1 & 2.8 & $558 \ddagger$ & 26 & $5.2(14.7)$ \\
\hline \multirow[t]{2}{*}{ COMRADE-B† } & $\begin{array}{l}\text { Ranibizumab } \\
0.5 \mathrm{mg}\end{array}$ & 6 & $\begin{array}{l}\text { 3xmonthly } \\
\text { doses, then } \\
\text { PRN }\end{array}$ & 4.9 & 124 & 57.9 & 65.6 & 2.0 & 537 & 61 & $17.0(11.2)$ \\
\hline & $\begin{array}{l}\text { Dexamethasone } \\
0.7 \mathrm{mg} \text { implant }\end{array}$ & 6 & $\begin{array}{l}1 \text { implant at } \\
\text { month } 0\end{array}$ & & 117 & 58.4 & 65.7 & 1.7 & 545 & 37 & $9.1(12.5)$ \\
\hline \multirow[t]{3}{*}{ RABAMES $^{22}$} & Laser & 6 & - & & 10 & 59.0 & 68.8 & 5.0 & 571 & 20 & $2(16.9)$ \\
\hline & $\begin{array}{l}\text { Ranibizumab } \\
0.5 \mathrm{mg}\end{array}$ & 6 & $\begin{array}{l}\text { 3xmonthly } \\
\text { doses }\end{array}$ & $\sim 3.0$ & 10 & 58.5 & 64.2 & 5.1 & 584 & 70 & $17(12.5)$ \\
\hline & $\begin{array}{l}\text { Laser+ranibizumab } \\
0.5 \mathrm{mg}\end{array}$ & 6 & $\begin{array}{l}\text { 3xmonthly } \\
\text { doses }\end{array}$ & $\sim 3.0$ & 10 & 64.5 & 65.9 & 6.0 & 506 & 70 & $6(9.3)$ \\
\hline \multirow{2}{*}{$\begin{array}{l}\text { Battaglia Parodi } \\
\text { et } a^{\beta}\end{array}$} & Laser & 3 and 12 & & & 33 & 65.6 & NA & NA & NA & NA & $9.7(13.2)$ \\
\hline & Control & 3 and 12 & & & 35 & 64.6 & NA & NA & NA & NA & $11.1(13.2)$ \\
\hline
\end{tabular}

Battaglia Parodi et $a^{\beta}$ decimal data are converted into BCVA letters.

${ }^{*}$ SDs were not reported in the VIBRANT publication, ${ }^{12}$ but were provided by the authors of the study.

†Data for BRAVO, BRIGHTER, COMRADE-B is reported after patient-level data analysis.

$\neq$ Central foveal thickness.

§In GENEVA, ${ }^{4}$ baseline characteristics were not split between patients with CRVO and those with BRVO. BCVA letters gained from the NICE assessment file entitled 'Evidence review:

dexamethasone implants (Ozurdex) for macular oedema after retinal vein occlusion (2010)'. SE of the mean was graphically estimated.

2q4, 2 mg monthly; BCVA, best-corrected visual acuity (assessed in terms of Early Treatment Diabetic Retinopathy Study letters); BRVO, branch retinal vein occlusion; CRT, central retinal

thickness; CRVO, central retinal vein occlusion; NA, not applicable; NICE, National Institute for Health and Care Excellence; PRN, pro re nata (as needed); RCT, randomised controlled trial. 
Table 3 The proportion of patients reporting IOP and OH adverse events from baseline to month 6 by study and treatment group

\begin{tabular}{|c|c|c|c|c|c|c|}
\hline Study & $\begin{array}{l}\text { Ranibizumab } \\
0.5 \mathrm{mg} \text { PRN, } \\
\mathrm{n} / \mathrm{N}(\%)\end{array}$ & $\begin{array}{l}\text { Aflibercept } \\
2 q 4, n / N(\%)\end{array}$ & $\begin{array}{l}\text { Laser, } \\
\text { n/N (\%) }\end{array}$ & $\begin{array}{l}\text { Sham, } \\
\text { n/N (\%) }\end{array}$ & $\begin{array}{l}\text { Dexamethasone } \\
0.7 \text { mg implant, } \\
\text { n/N (\%) }\end{array}$ & $\begin{array}{l}\text { Ranibizumab } \\
0.5 \text { mg PRN+laser } \\
\text { photocoagulation, } \\
\mathrm{n} / \mathrm{N}(\%)\end{array}$ \\
\hline BRAVO $^{9}$ & $7 / 130(5)$ & & & 2/131 (2) & & \\
\hline VIBRANT $^{12}$ & & 2/91 (2) & 0/92 (0) & & & \\
\hline Tan et $a^{p 7}$ & Not reported & & Not reported & & & \\
\hline GENEVA $^{14}$ & & & & $4 / 276(1)$ & $82 / 288$ (28) & \\
\hline COMRADE-B ${ }^{33 *}$ & 2/126 (2) & & & & $24 / 118(20)$ & \\
\hline BRIGHTER ${ }^{32}$ & 6/180 (3) & & $1 / 88(1 \%)$ & & & 12/183 (7) \\
\hline $\begin{array}{l}\text { Battaglia Parodi } \\
\text { et } a \beta^{\beta}\end{array}$ & & & Not reported & Not reported & & \\
\hline RABAMES $^{22}$ & $0 / 10(0)$ & & 0/10 (0) & & & 0/10 (0) \\
\hline Total & $15 / 446(3)$ & 2/91 (2) & $1 / 190(1)$ & $6 / 407(1)$ & $106 / 406(26)$ & $12 / 193(6)$ \\
\hline \multicolumn{7}{|c|}{ 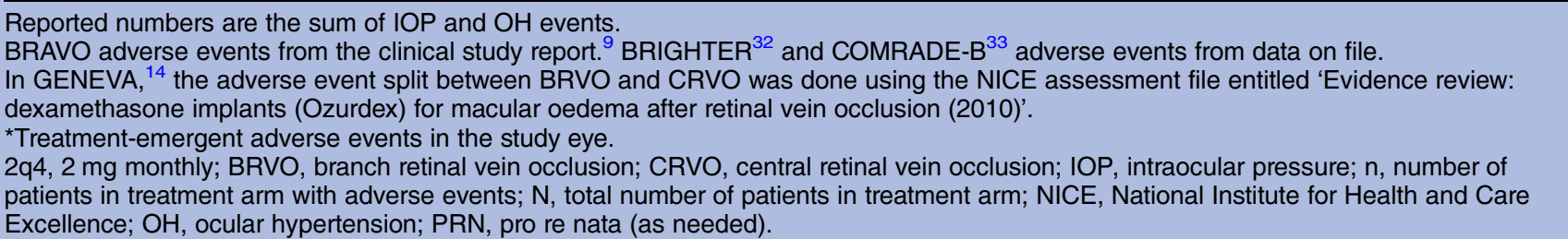 } \\
\hline
\end{tabular}

\section{Node-splitting analysis}

The node-splitting results are presented in online supplementary table 4 . The model showed an incremental gain $(95 \% \mathrm{CrI})$ of 7.8 letters (1.8 to 13.8$)$ for ranibizumab monotherapy versus dexamethasone implant from the direct evidence (COMRADE- $\mathrm{B}^{33}$ ), whereas the indirect evidence (all trials except COMRADE- ${ }^{33}$ ) provided an incremental gain of 8.1 letters (0.8-15.5). This difference between direct and indirect evidence was nonsignificant $(p=0.93)$. Similarly, there was no statistically significant difference between the $\operatorname{direct}^{8}$ and indirect evidence of the relative efficacy of laser monotherapy versus sham intervention. The difference between direct and indirect evidence was higher when considering the

Table 4 Incremental BCVA letters gained at 6 months versus laser therapy alone (random treatment effects model)

\begin{tabular}{|c|c|}
\hline Treatment & $\begin{array}{l}\text { Incremental letters } \\
\text { gained vs laser } \\
\text { photocoagulation alone }\end{array}$ \\
\hline Ranibizumab $0.5 \mathrm{mg}$ PRN & $11.5(7.5 \text { to } 15.9)^{*}$ \\
\hline $\begin{array}{l}\text { Ranibizumab } 0.5 \mathrm{mg} \text { PRN } \\
\text { +laser photocoagulation }\end{array}$ & $10.1(5.1 \text { to } 15.3)^{*}$ \\
\hline $\begin{array}{l}\text { Dexamethasone } 0.7 \mathrm{mg} \\
\text { implant }\end{array}$ & $3.5(-1.6$ to 9.1$)$ \\
\hline Aflibercept 2q4 & $10.2(4.6 \text { to } 15.5)^{\star}$ \\
\hline Sham & $1.0(-3.5$ to 5.9$)$ \\
\hline \multicolumn{2}{|c|}{$\begin{array}{l}{ }^{*} \mathrm{p}<0.05 \text {. } \\
\text { Studies included in the base case analysis are VIBRANT, }{ }^{12} \\
\text { BRAVO, }{ }^{9} \text { BRIGHTER, }{ }^{32} \text { COMRADE-B, }{ }^{33} \text { Tan et al, }{ }^{27} \text { Battaglia } \\
\text { Parodi et al, }{ }^{8} \text { GENEVA. }{ }^{14} \\
2 q 4,2 \text { mg monthly; BCVA, best corrected visual acuity; PRN, pro } \\
\text { re nata (as needed). }\end{array}$} \\
\hline
\end{tabular}

incremental efficacy of ranibizumab monotherapy over laser monotherapy (2.5 letter difference between the indirect and the direct evidence), although this difference remained non-significant $(\mathrm{p}=0.61)$.

The choice of a random effects model (rather than a fixed effects model) was justified because of the heterogeneity among trials (between-study SD 1.2). However, the fixed effects model provided similar results to the random effects model, with ranibizumab monotherapy having a $63 \%$ probability of being the best treatment (in terms of letters gained) compared with $27 \%$ for aflibercept, $10 \%$ for ranibizumab plus laser and $0 \%$ for dexamethasone implant, laser and sham.

\section{Sensitivity analyses}

The sensitivity analyses results are summarised in figures 4 and 5 (see online supplementary materials). Including RABAMES $^{22}$ in the network had limited impact on the results. Mean (95\% CrI) BCVA letters gained from baseline for ranibizumab monotherapy over aflibercept remained non-statistically significant $(+1.7(-4.7$ to 9.1$))$, and the probability of ranibizumab monotherapy being the best treatment based on letters gained increased to $68 \%$, compared with $27 \%$ for aflibercept and $5 \%$ for ranibizumab plus laser. The inclusion of RABAMES ${ }^{22}$ slightly increased the ranibizumab numerical advantage in terms of percentage of patients gaining at least 15 letters (OR vs aflibercept $1.2(0.3$ to 7.8$)$ ). The probability that ranibizumab monotherapy was the best treatment increased from $35 \%$ to $40 \%$ (vs $30 \%$ for aflibercept, $28 \%$ for ranibizumab plus laser and $1 \%$ for dexamethasone implant). When data from the study by Battaglia Parodi $e t a l^{8}$ were excluded from the network, patients receiving ranibizumab monotherapy showed a non-significant mean $(95 \% \mathrm{CrI})$ gain of 
Table 5 Pairwise ORs $(95 \% \mathrm{Crl})$ for gaining $\geq 15$ letters from baseline (random treatment effects model)

\begin{tabular}{|c|c|c|c|c|c|c|}
\hline Comparator & Sham & $\begin{array}{l}\text { Ranibizumab } \\
0.5 \mathrm{mg} \text { PRN }\end{array}$ & Aflibercept $2 q 4$ & $\begin{array}{l}\text { Laser } \\
\text { photocoagulation }\end{array}$ & $\begin{array}{l}\text { Dexamethasone } \\
0.7 \mathrm{mg} \text { implant }\end{array}$ & $\begin{array}{l}\text { Ranibizumab } 0.5 \mathrm{mg} \\
\text { PRN+laser } \\
\text { photocoagulation }\end{array}$ \\
\hline Sham & - & & & & & \\
\hline $\begin{array}{l}\text { Ranibizumab } 0.5 \text { mg } \\
\text { PRN }\end{array}$ & $3.53(1.02 \text { to } 12.67)^{\star}$ & - & $1.06(0.16$ to 8.94$)$ & $3.24(1.03 \text { to } 12.56)^{\star}$ & & \\
\hline Aflibercept 2q4 & $3.38(0.28$ to 31.36$)$ & $0.95(0.11$ to 6.17$)$ & - & 3.07 (0.63 to 14.75$)$ & & \\
\hline Laser photocoagulation & $1.11(0.17$ to 5.68$)$ & $0.31(0.08 \text { to } 0.97)^{*}$ & 0.33 (0.07 to 1.59$)$ & - & & \\
\hline $\begin{array}{l}\text { Dexamethasone } 0.7 \mathrm{mg} \\
\text { implant }\end{array}$ & $1.22(0.35$ to 4.38$)$ & 0.35 (0.09 to 1.24$)$ & 0.36 (0.04 to 4.54$)$ & 1.11 (0.21 to 7.39$)$ & - & \\
\hline $\begin{array}{l}\text { Ranibizumab } 0.5 \mathrm{mg} \\
\text { PRN+laser } \\
\text { photocoagulation }\end{array}$ & 3.18 (0.43 to 20.98$)$ & 0.89 (0.19 to 3.76$)$ & 0.94 (0.11 to 8.85$)$ & 2.87 (0.67 to 13.88$)$ & $2.59(0.33$ to 17.21$)$ & - \\
\hline
\end{tabular}

Table 6 Pairwise difference $(95 \% \mathrm{Crl})$ for letters gained from baseline (random treatment effects model)

\begin{tabular}{|c|c|c|c|c|c|c|}
\hline Comparator & Sham & $\begin{array}{l}\text { Ranibizumab } \\
0.5 \mathrm{mg} \text { PRN }\end{array}$ & Aflibercept $2 q 4$ & $\begin{array}{l}\text { Laser } \\
\text { photocoagulation }\end{array}$ & $\begin{array}{l}\text { Dexamethasone } \\
0.7 \mathrm{mg} \text { implant }\end{array}$ & $\begin{array}{l}\text { Ranibizumab } 0.5 \mathrm{mg} \\
\text { PRN+laser } \\
\text { photocoagulation }\end{array}$ \\
\hline Sham & - & & & & & \\
\hline Ranibizumab $0.5 \mathrm{mg}$ PRN & $10.6(6.9 \text { to } 14.2)^{*}$ & - & & & & \\
\hline Aflibercept $2 q 4$ & $9.2(1.7 \text { to } 16.1)^{*}$ & $-1.4(-8.5$ to 5.2$)$ & - & & & \\
\hline Laser photocoagulation & $-1.0(-5.9$ to 3.5$)$ & $-11.5(-15.9 \text { to }-7.5)^{*}$ & $-10.2(-15.5 \text { to } 4.6)^{*}$ & - & & \\
\hline $\begin{array}{l}\text { Dexamethasone } 0.7 \mathrm{mg} \\
\text { implant }\end{array}$ & $2.5(-1.1$ to 6.3$)$ & $-8.0(-11.9 \text { to }-4.0)^{*}$ & $-6.7(-14.0$ to 1.3$)$ & $3.5(-1.6$ to 9.1$)$ & - & \\
\hline $\begin{array}{l}\text { Ranibizumab } 0.5 \mathrm{mg} \text { PRN } \\
\text { +laser photocoagulation }\end{array}$ & $9.2(3.4 \text { to } 14.5)^{\star}$ & $-1.4(-6.3$ to 3.1$)$ & $-0.0(-7.4$ to 7.6$)$ & $10.1(5.1 \text { to } 15.3)^{*}$ & $6.6(0.4$ to 12.3$)$ & - \\
\hline
\end{tabular}




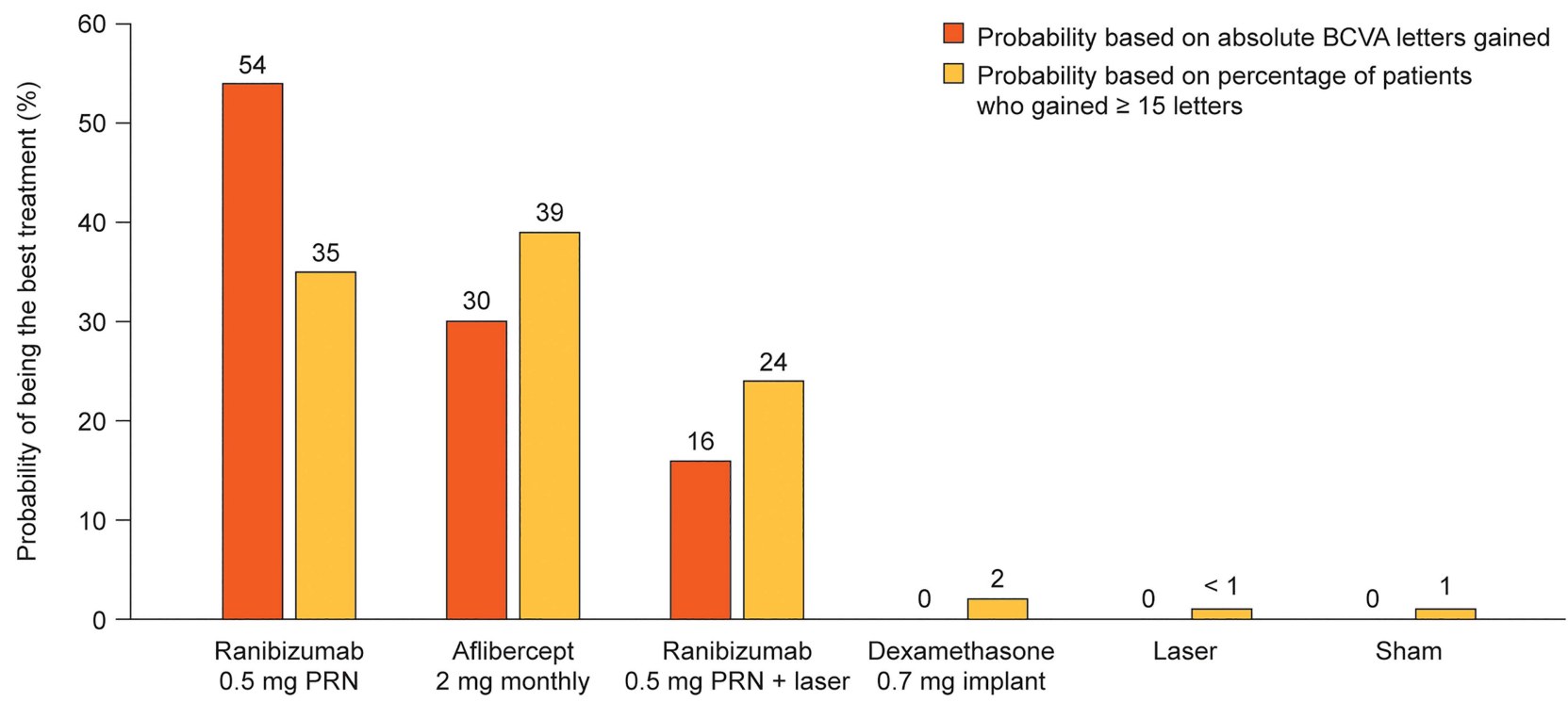

Figure 3 Probability that each treatment is the most efficacious in the study network. BCVA assessed in terms of ETDRS letters. BCVA, best corrected visual acuity; ETDRS, Early Treatment Diabetic Retinopathy Study; PRN, pro re nata (as needed).

1.4 letters (-6.3 to 9.5) over aflibercept. After excluding data from Tan $e t a l^{27}$ from the network, patients receiving ranibizumab monotherapy showed a non-significant mean (95\% CrI) gain of 1.3 letters (-6.2 to 8.6) compared with those receiving aflibercept. When removing Tan et al or Battaglia Parodi et $a l^{8}{ }^{8}$ ranibizumab monotherapy remained the agent with the highest probability of being the best treatment (52\%, both). We attempted to analyse the rates of increased $\mathrm{IOP} / \mathrm{OH}$ when results for ranibizumab and aflibercept were not combined. However, it was not possible to compare the relative rates of events between the two anti-VEGF therapies because the model did not converge.

\section{DISCUSSION}

Glanville $e t a l^{19}$ concluded that it was not possible to conduct a network meta-analysis in BRVO owing to

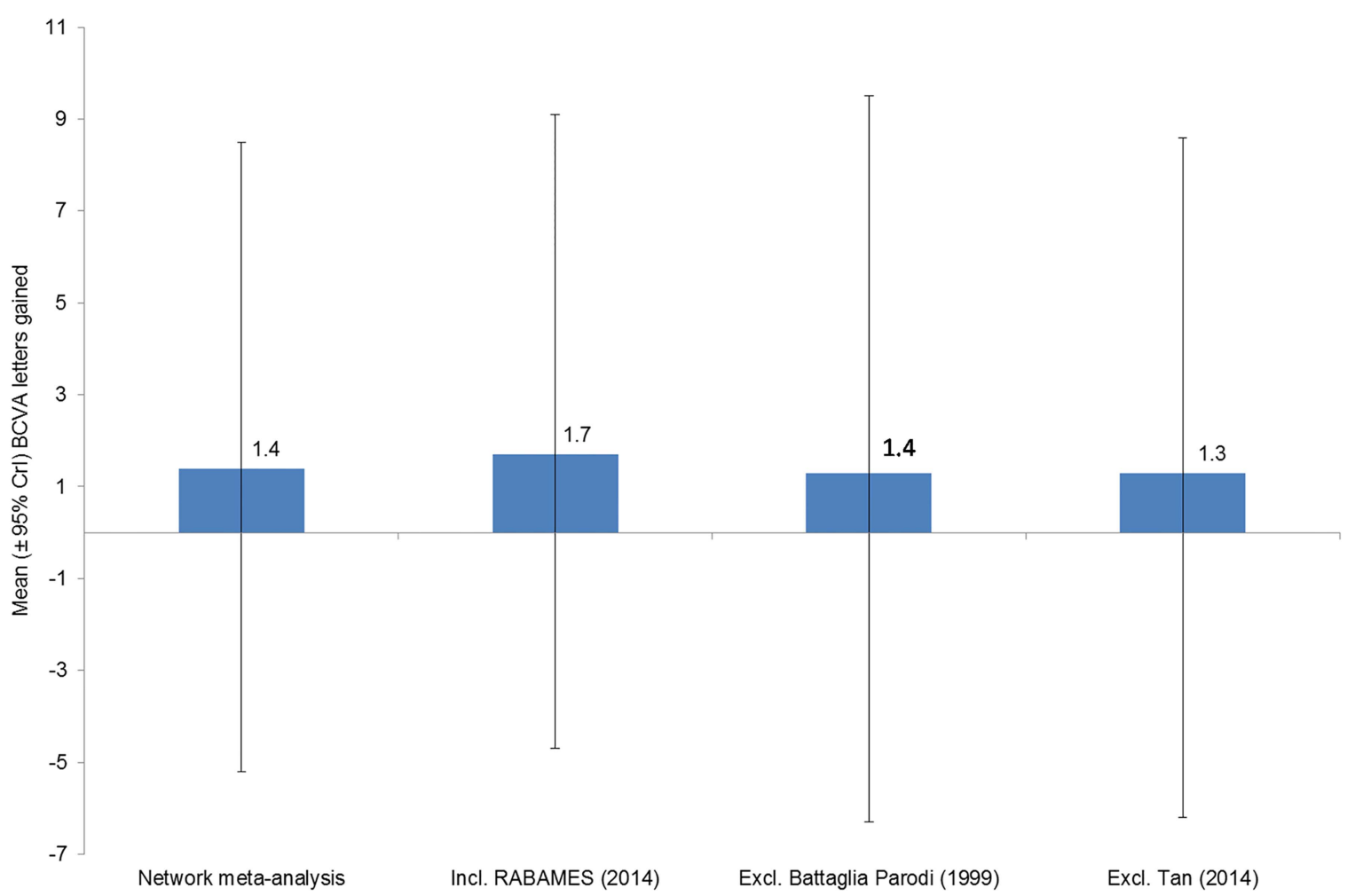

Figure 4 Sensitivity analysis: mean best corrected visual acuity (BCVA) letters gained from baseline for ranibizumab monotherapy over aflibercept. 


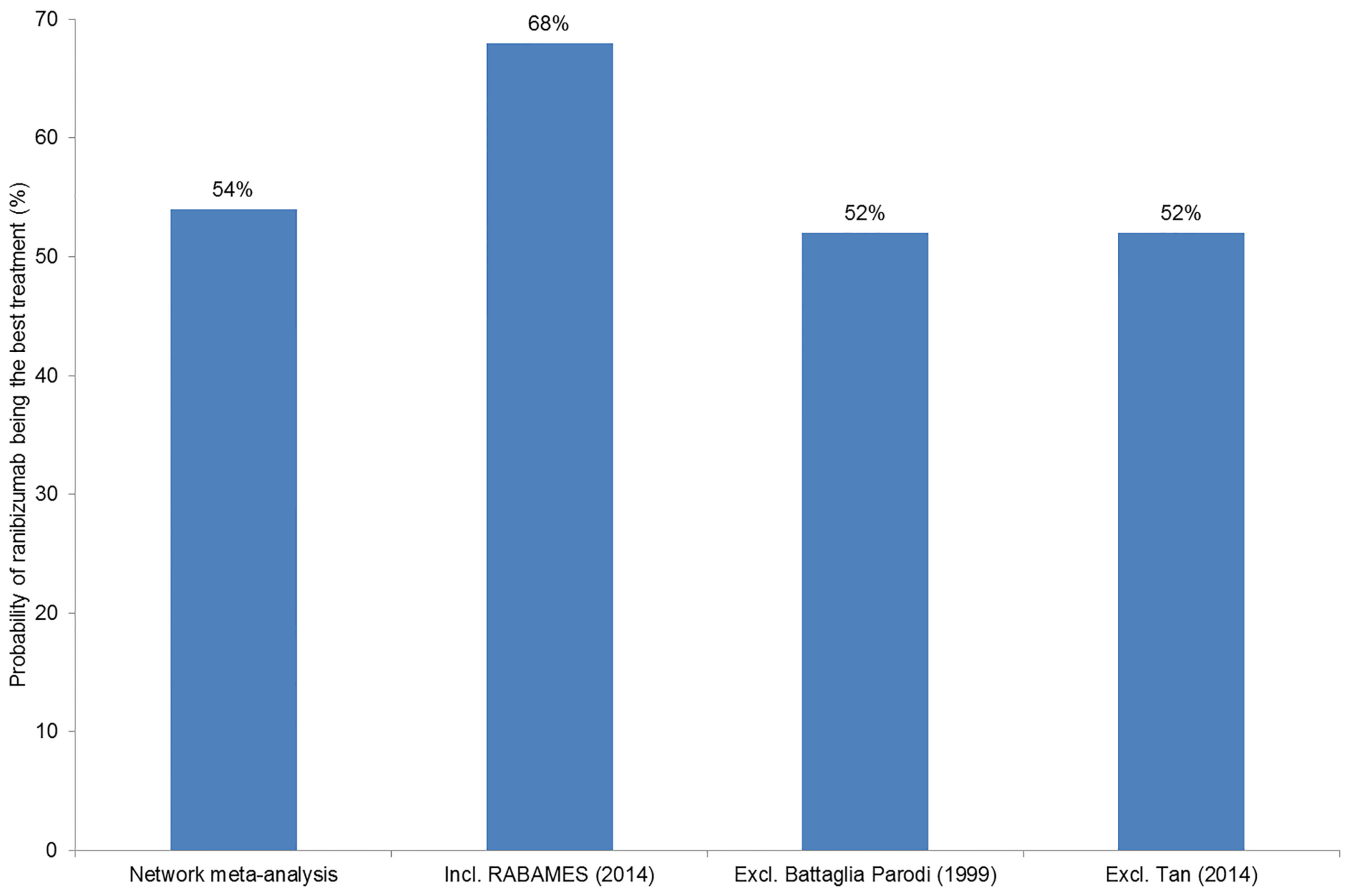

Figure 5 Sensitivity analysis: probability that ranibizumab monotherapy is the most efficacious treatment based on best corrected visual acuity (BCVA) letters gained from baseline.

interstudy differences in design and baseline characteristics. However, the BRVO analysis in their study included only three studies, BRAVO, ${ }^{23}$ Battaglia Parodi et $a l^{8}$ and GENEVA. ${ }^{14}$ Since November 2010, when Glanville et al conducted the searches for their review, the preliminary results of new clinical trials were made available, allowing the network meta-analysis described here to be conducted. Specifically, BRIGHTER ${ }^{32}$ enables comparison between laser therapy and ranibizumab monotherapy, and also between laser therapy and ranibizumab+laser combination therapy; COMRADE-B ${ }^{33}$ allows direct comparison between ranibizumab monotherapy and dexamethasone implant, and VIBRANT ${ }^{12}$ provides information on aflibercept versus laser therapy.

In general, the results from this network meta-analysis confirm the results from head-to-head clinical trials. In particular, our analysis confirms that anti-VEGF monotherapies are more efficacious than laser therapy, as shown in VIBRANT, ${ }^{12}$ BRIGHTER, ${ }^{32}$ RABAMES $^{22}$ and by Tan $e$ al..$^{27}$ Our results also confirm the superiority, in terms of letters gained in BCVA, of ranibizumab monotherapy over dexamethasone implant, as shown in COMRADE-B. ${ }^{33}$ A key finding was that the efficacy of laser was similar to sham intervention, suggesting that the role of laser in the treatment of BRVO should be reappraised. The CrIs were broad and there was no statistically significant difference between ranibizumab $0.5 \mathrm{mg}$ PRN and aflibercept $2 q 4$ in either letters gained or proportion of patients gaining more than 15 letters.

The results were shown to be robust in a number of sensitivity analyses, including an analysis from which trials that did not report outcomes at 6 months were excluded, and an analysis in which a trial with only three injections in the first 6 months was included. In addition, there was no evidence of inconsistency between direct and indirect evidence. It was not possible to compare adverse event rates between ranibizumab monotherapy and aflibercept monotherapy because the model did not converge owing to the low incidence of increased IOP/OH. This meant that we had to merge ranibizumab and aflibercept treatments into an anti-VEGF therapy group. Similarly, the incidence of systemic adverse events was not analysed. The lack of convergence does not mean that there are no differences in increased $\mathrm{IOP} / \mathrm{OH}$ rates between treatments: it could mean that the included studies did not have sufficient power to detect any such differences. A preliminary analysis indicated that two samples of 2525 individuals would be required to reach a power of $80 \%$ to detect significant differences between treatments if the event rates were $1-2 \%$. Hence, analyses of real-world data could shed some light on the relative safety and tolerability of anti-VEGF and dexamethasone implant therapy and help to refine the full benefit-to-risk ratio of approved treatments for macular oedema secondary to BRVO.

The retreatment period for dexamethasone implant in the clinical trials was 6 months. Therefore, we used a 6-month perspective to evaluate the relative efficacy of dexamethasone implant. However, based on the GENEVA $^{14}$ and COMRADE-B ${ }^{33}$ trials, the efficacy (and rate of increased $\mathrm{IOP} / \mathrm{OH}$ ) of dexamethasone implant peaks at month 2 before decreasing at month 6 . While we cannot formally determine how dexamethasone implant would have performed with a 2-month retreatment regimen, the BCVA was 2.9 letters higher at month 2 than month 6 in GENEVA ${ }^{14}$ and approximately 4.5 letters 
higher at month 2 than month 6 in COMRADE-B. ${ }^{33}$ Therefore, a bi-monthly retreatment regimen for dexamethasone implants may reduce the efficacy advantage of ranibizumab $0.5 \mathrm{mg}$ PRN found in this network meta-analysis $(+8.0$ (4.0 to 11.9) letters vs dexamethasone implant). Additional trials assessing the efficacy and safety of bimonthly or trimonthly dexamethasone would be useful, allowing us to investigate this issue.

The results presented here indicate that the value of adjunctive laser photocoagulation therapy for macular oedema secondary to BRVO is uncertain. Our analysis was not able to demonstrate that the combination of laser and ranibizumab therapy provided higher efficacy gains than ranibizumab monotherapy. In addition, in BRIGHTER, ${ }^{32}$ the mean (SD) number of ranibizumab injections was similar for the combination (4.5 (1.2) injections) and ranibizumab monotherapy arms (4.8 (1.0) injections). Therefore, it is not clear whether adjunctive laser therapy would decrease the ranibizumab injection costs.

The main challenge in any network meta-analysis is to compare studies that may have different populations (eg, owing to different inclusion/exclusion criteria). The key strength of the present analysis is that inclusion/exclusion criteria for baseline BCVA and duration of disease were matched in three trials containing anti-VEGF therapies. Those two variables (baseline BCVA and duration of disease) have shown to influence the outcome in RVO and need to be accounted for in order to reduce the risk of heterogeneity. ${ }^{35}$ Indeed, when the ranibizumab clinical trials ${ }^{932} 33$ were analysed without matching key inclusion/exclusion criteria to those of VIBRANT, ${ }^{12}$ there were no differences in letters gained between ranibizumab $0.5 \mathrm{mg}$ PRN and aflibercept $2 \mathrm{q} 4$ (0.0 letters ( -6.7 to 7.5)). This demonstrates the importance of adjusting for baseline characteristics that influence clinical outcomes. In theory, a meta-regression with baseline BCVA and duration of disease as covariates could be run to account for heterogeneity. However, the coefficients for baseline BCVA or duration of disease did not converge (potentially because of the lack of degrees of freedom in the network).

The main limitation of the study is that, at the time of completion of this manuscript, two clinical trials were not yet published in the peer-reviewed literature and therefore, their quality could not be assessed. A second limitation was that the SEs of the BCVA gains in GENEVA $^{34}$ were only graphically estimated because these were not reported in the study. However, this assumption had a limited impact on the results. If we increase the SDs to 8.5 for the sham arm and to 8.7 for the dexamethasone implant arm (corresponding to a $95 \%$ CI of \pm 1 letter for the estimated mean in GENEVA), ${ }^{34}$ the results remain similar: the ranibizumab $0.5 \mathrm{mg}$ PRN advantage over dexamethasone implant remains at 8.0 (4.0 to 11.9) letters. A further limitation was that the definition of increased IOP was not usually reported in the publications and it was not possible to assess whether there were substantial differences and, if so, whether the differences were relevant. Finally, data from only a limited number of trials were included in this analysis, and future analyses will be strengthened once additional clinical trial data becomes available.

\section{CONCLUSIONS}

This Bayesian network meta-analysis confirmed the superiority of ranibizumab monotherapy over dexamethasone implant or laser for the treatment of macular oedema secondary to BRVO, and showed that there were no statistical differences between ranibizumab monotherapy and aflibercept.

Acknowledgements Medical writing support was provided by Fernando Gibson, PhD, and Robert Gillies, PhD, of PharmaGenesis London.

Contributors SAR designed the study, collected the data, ran the network meta-analysis, wrote and approved the manuscript. ML identified the relevant end points, discussed the validity of the trials, revised and approved the manuscript. VB re-analysed BRAVO and BRIGHTER data to match VIBRANT inclusion/exclusion criteria and approved the manuscript. FA conducted the systematic review, evaluated the quality of the studies, participated in the elaboration of the manuscript and approved the manuscript.

Competing interests This study was funded by Novartis Pharma AG. The funder provided support in the form of salaries for authors SAR, FA and VB. However, Novartis Pharma AG and Genentech Inc. reviewed the manuscript before submission. Third-party medical writing assistance was funded by Novartis Pharma AG. ML has received financial support and/or consulting fees from Novartis AG, Bayer, Allergan, Roche, GlaxoSmithKline, AstraZeneca and Novo Nordisk. Novartis has exclusive rights to market ranibizumab outside the USA and Genentech has exclusive rights to market ranibizumab in the USA.

Provenance and peer review Not commissioned; externally peer reviewed.

Data sharing statement The statistical code used for this analysis is available on request for academic use.

Open Access This is an Open Access article distributed in accordance with the Creative Commons Attribution Non Commercial (CC BY-NC 4.0) license, which permits others to distribute, remix, adapt, build upon this work noncommercially, and license their derivative works on different terms, provided the original work is properly cited and the use is non-commercial. See: http:// creativecommons.org/licenses/by-nc/4.0/

\section{REFERENCES}

1. Rehak J, Rehak M. Branch retinal vein occlusion: pathogenesis, visual prognosis, and treatment modalities. Curr Eye Res 2008;33:111-31.

2. Green WR, Chan CC, Hutchins GM, et al. Central retinal vein occlusion: a prospective histopathologic study of 29 eyes in 28 cases. Trans Am Ophthalmol Soc 1981;79:371-422.

3. Hayreh SS, Zimmerman MB, Podhajsky P. Incidence of various types of retinal vein occlusion and their recurrence and demographic characteristics. Am J Ophthalmol 1994;117:429-41.

4. Mclntosh RL, Rogers SL, Lim L, et al. Natural history of central retinal vein occlusion: an evidence-based systematic review. Ophthalmology 2010;117:1113-23.

5. Rogers S, Mclntosh RL, Cheung N, et al. The prevalence of retinal vein occlusion: pooled data from population studies from the United States, Europe, Asia, and Australia. Ophthalmology 2010;117:313-19.

6. Finkelstein D. Argon laser photocoagulation for macular edema in branch vein occlusion. Ophthalmology 1986;93:975-7.

7. The Branch Vein Occlusion Study Group. Argon laser photocoagulation for macular edema in branch vein occlusion. Am J Ophthalmol 1984;98:271-82. 
8. Battaglia Parodi M, Saviano S, Ravalico G. Grid laser treatment in macular branch retinal vein occlusion. Graefes Arch Clin Exp Ophthalmol 1999;237:1024-7.

9. Brown DM, Campochiaro PA, Singh RP, et al. Ranibizumab for macular edema following central retinal vein occlusion: six-month primary end point results of a phase III study. Ophthalmology 2010;117:1124-33.

10. Genentech Press Release 2012. FDA Approves Lucentis $\circledR$ (Ranibizumab Injection) for the Treatment of Macular Edema Following Retinal Vein Occlusion. http://www.gene.com/media/pressreleases/12827/2010-06-22/fda-approves-lucentis-ranibizumab-inject (accessed 12 Nov 2014)

11. Novartis Europharm Limited 2014. Lucentis $\AA$ (ranibizumab) Summary of Product Characteristics. http://www.ema.europa.eu/ docs/en_GB/document library/EPAR_-_Product_Information/human/ 000715/WC500043546.pdf (accessed 12 Nov 2014)

12. Campochiaro PA, Clark WL, Boyer DS, et al. Intravitreal aflibercept for macular edema following branch retinal vein occlusion: the 24-week results of the VIBRANT study. Ophthalmology 2015; 122:538-44.

13. Regeneron. EYLEA® (aflibercept) Injection Submitted for EU Marketing Authorization for the Treatment of Patients with Macular Edema Secondary to Branch Retinal Vein Occlusion (BRVO). 2014. http://files.shareholder.com/downloads/REGN/3424387345x0x 761325/f94e4471-a4bc-45c9-b44a-a7b6aab4e66b/REGN_News_ 2014611 General Releases.pdf

14. Haller JA, Bandello F, Belfort R Jr, et al. Randomized, shamcontrolled trial of dexamethasone intravitreal implant in patients with macular edema due to retinal vein occlusion. Ophthalmology 2010;117:1134-46.

15. Haller JA, Bandello F, Belfort R Jr, et al. Dexamethasone intravitreal implant in patients with macular edema related to branch or central retinal vein occlusion twelve-month study results. Ophthalmology 2011;118:2453-60.

16. McAllister IL, Vijayasekaran S, Chen SD, et al. Effect of triamcinolone acetonide on vascular endothelial growth factor and occludin levels in branch retinal vein occlusion. Am J Ophthalmol 2009; 147:838-46

17. Scott IU, Ip MS, VanVeldhuisen PC, et al. A randomized trial comparing the efficacy and safety of intravitreal triamcinolone with standard care to treat vision loss associated with macular edema secondary to branch retinal vein occlusion: the Standard Care vs Corticosteroid for Retinal Vein Occlusion (SCORE) study report 6. Arch Ophthalmol 2009;127:1115-28.

18. Ip MS, Scott IU, VanVeldhuisen PC, et al. A randomized trial comparing the efficacy and safety of intravitreal triamcinolone with observation to treat vision loss associated with macular edema secondary to central retinal vein occlusion: the Standard Care vs Corticosteroid for Retinal Vein Occlusion (SCORE) study report 5. Arch Ophthalmol 2009;127:1101-14.

19. Glanville J, Patterson J, McCool R, et al. Efficacy and safety of widely used treatments for macular oedema secondary to retinal vein occlusion: a systematic review. BMC Ophthalmol 2014:14:7.

20. National Institute for Health and Care Excellence 2012. Appendix C: methodology checklist: randomised controlled trials. http:// publications.nice.org.uk/the-guidelines-manual-appendices-bipmg6b/appendix-c-methodology-checklist-randomised-controlledtrials (accessed 13 Nov 2014).
21. Ford JA, Elders $A$, Shyangdan $D$, et al. The relative clinical effectiveness of ranibizumab and bevacizumab in diabetic macular oedema: an indirect comparison in a systematic review. $B M J$ 2012;345:e5182.

22. Pielen A, Mirshahi A, Feltgen N, et al. Ranibizumab for Branch Retinal Vein Occlusion Associated Macular Edema Study (RABAMES): six-month results of a prospective randomized clinical trial. Acta Ophthalmol 2015;93:e29-37.

23. Campochiaro PA, Heier JS, Feiner L, et al. Ranibizumab for macular edema following branch retinal vein occlusion: six-month primary end point results of a phase III study. Ophthalmology 2010;117:1102-12.

24. Moradian S, Faghihi H, Sadeghi B, et al. Intravitreal bevacizumab vs. sham treatment in acute branch retinal vein occlusion with macular edema: results at 3 months (report 1). Graefes Arch Clin Exp Ophthalmol 2011;249:193-200.

25. Russo V, Barone A, Conte E, et al. Bevacizumab compared with macular laser grid photocoagulation for cystoid macular edema in branch retinal vein occlusion. Retina 2009;29: 511-15.

26. Kuppermann BD, Blumenkranz MS, Haller JA, et al. Randomized controlled study of an intravitreous dexamethasone drug delivery system in patients with persistent macular edema. Arch Ophthalmol 2007;125:309-17.

27. Tan MH, McAllister IL, Gillies ME, et al. Randomized controlled trial of intravitreal ranibizumab versus standard grid laser for macular edema following branch retinal vein occlusion. Am J Ophthalmol 2014; 157:237-47.

28. Brown DM, Campochiaro PA, Bhisitkul RB, et al. Sustained benefits from ranibizumab for macular edema following branch retinal vein occlusion: 12-month outcomes of a phase III study. Ophthalmology 2011:118:1594-602.

29. Campochiaro PA, Hafiz G, Channa R, et al. Antagonism of vascular endothelial growth factor for macular edema caused by retinal vein occlusions: two-year outcomes. Ophthalmology 2010;117:2387-94.

30. Pichi F, Specchia C, Vitale L, et al. Combination therapy with dexamethasone intravitreal implant and macular grid laser in patients with branch retinal vein occlusion. Am J Ophthalmol 2014:157:607-15.

31. Azad R, Vivek K, Sharma Y, et al. Ranibizumab as an adjunct to laser for macular edema secondary to branch retinal vein occlusion. Indian J Ophthalmol 2012;60:263-6.

32. Novartis Pharmaceuticals 2014. Efficacy and Safety of Ranibizumab With or Without Laser in Comparison to Laser in Branch Retinal Vein Occlusion (BRIGHTER). http://clinicaltrials.gov/show/NCT01599650 (accessed 14 Nov 2014)

33. Hattenbach L-O. Efficacy and Safety of $0.5 \mathrm{mg}$ Ranibizumab compared with $0.7 \mathrm{mg}$ dexamethasone intravitreal implant in patients with branch retinal vein occlusion over 6 months: the COMRADE-B study. Invest Ophthalmol Vis Sci 2014;55:1830.

34. Allergan 2005. A Study of the Safety and Efficacy of a New Treatment for Macular Edema Resulting From Retinal Vein Occlusion. http://ClinicalTrials.gov/show/NCT00168324 (accessed 14 Nov 2014)

35. Ford JA, Lois N, Royle $\mathrm{P}$, et al. Current treatments in diabetic macular oedema: systematic review and meta-analysis. BMJ Open 2013;3:e002269. 